\title{
Medical Education: Effectiveness of Two Simulation Teaching Methods in Developing Intubation Skills of Year Level Six Medical Students (Clinical Clerks)
}

\author{
Ryner Jose DC Carrillo, ${ }^{1}$ Nomar M. Alviar, ${ }^{2}$ Leo Daniel D. Caro, ${ }^{1}$ Ruzanne M. Caro, ${ }^{1}$ Armando C. Crisostomo, ${ }^{1}$ \\ Lorna R. Cruz, ${ }^{1}$ Heizel Manapat-Reyes ${ }^{1}$ and Fernando E. Serra ${ }^{1}$ \\ ${ }^{1}$ College of Medicine, University of the Philippines Manila \\ ${ }^{2}$ National Teacher Training Center, University of the Philippines Manila
}

\begin{abstract}
Objective. To describe outcomes of two simulation teaching methods in developing intubation skills of year level six medical students (clinical clerks).

Methods. Students were shown a 6-minute video on intubation. Students were exposed to video-assisted learning, videoassisted learning with instructor-guided simulation, and videoassisted learning with experiential learning. Each student was assessed by a non-graded 11 point objective structured clinical examination.
\end{abstract}

Results and Discussion. The three learning strategies: 1. Videoassisted learning, 2. Video-assisted learning with instructorguided simulation, 3. Video-assisted learning with experiential learning (self-discovery learning) simulation showed OSCE mean scores (standard deviations) of 5.76 (2.16), 7.21 (2.35) and 7.60 (1.72), respectively. Failure of intubation was $21 \%$ (8/38), $2 \%$ $(1 / 40)$ and $0 \%(0 / 36)$, respectively. There is an absolute risk reduction of $27-30 \%$ in failure of intubation when either VGL or VEL is used. Students recognized the contribution of the simulation-based activities to the development of their intubation skills. They appreciated the opportunity to actually perform intubation in a rehearsal setting before doing the procedure on real patients.

Conclusion. Medical simulation enhanced student skills development. Experiential learning or self-discovery learning method may be as effective as instructor guided simulation.

Key Words: intubation, medical simulation, experiential learning

Presented at the First ASEAN Patient Safety Congress, June 26, 2015, Sofitel Hotel, Pasay City, Philippines.

Corresponding author: Ryner Jose DC Carillo, MD

Department of Otorhinolaryngology

2nd Floor, Ward 10

Philippine General Hospital

University of the Philippines Manila

Taft Avenue, Ermita, Manila 1000 Philippines

Telephone: +6325548400 local 2151 or 2152

Email: ryner_c@yahoo.com

\section{Introduction}

The University of the Philippines College of Medicine has adopted teaching innovations from traditional learning, problem-based learning to integrated organ systems. These learning strategies allow the college to improve students' acquisition of knowledge, attitudes and skills in medicine. Effective and efficient teaching strategies are developed in order to give full potential to students and trainees, the college being its own laboratory.

Patient safety is a major thrust of medical education. Simulation has been proven to enhance learning in medical education and promoting patient safety. Simulation in medical education may improve learning of medical skills in the UP College of Medicine. Factors affecting acceptability and effectiveness of the program will guide the college in developing simulation models in different medical educational levels and specialties.

\section{Literature Review}

Simulation in medicine has been proven effective at different levels of learning. ${ }^{1}$ From cardiac auscultation to laparoscopic surgery, simulation technology allows acquisition of knowledge and skills prior to direct patient participation. At varying cost and effectiveness, compared to no intervention, technology-enhanced simulation is associated with large effects in gaining knowledge, skills and attitudes, and moderate effects in patient-related outcomes. $^{2}$

Intubation is one of the most important skills in securing the airway. This has been an important component of basic and advanced cardiac life support skills. More often than not, students get to do the procedure with supervision only a few times during their medical clerkship and internship. It is a skill that should be done competently with high level of patient safety even during training.

Simulation of intubation may increase the competency of the trainee in doing the procedure. However, evidence suggests that experiential learning, where the trainee figures out the steps in the procedure by himself, provides faster learning as compared to a guided one. ${ }^{3}$ For this reason, there is a need to evaluate competency in 
acquisition of knowledge and skills in endotracheal intubation using didactics, guided simulation or experiential learning.

Current literature on simulation studies in doing endotracheal intubation employ visual display and haptic feedback utilizing advances in computer technology. Virtual intubation was compared to simulation using mannequin. Greater success in intubation is observed in subjects using mannequin while objective structured clinical examination (OSCE) scores did not differ. ${ }^{4}$

Acquiring skills in endotracheal intubation using different methods is important in medical students as they may use the skill in advanced cardiac life support. However, it is important to emphasize preparedness using checklist, team approach, and scenario-based training. ${ }^{5}$ This study limits itself in the acquisition of actual endotracheal intubation skills on simple controlled scenario. Scenariobased training using medical simulation may be investigated in higher levels of training, e.g., residency and fellowship, to address difficult airway management. ${ }^{6}$ The use of simulation prior to actual patient exposure also allows the students to develop higher level of attitude and behavior when doing endotracheal intubation. ${ }^{7}$

\section{Objectives}

\section{General Objective:}

To describe outcomes of two simulation teaching methods in developing intubation skills of year level six medical students (clinical clerks).

\section{Specific Objectives:}

1. To compare effectiveness of video-assisted learning, video-assisted learning with guided simulation, and video-assisted learning with experiential learning in intubation using OSCE scores and successful intubation as outcomes

2. To determine the factors that influence learning with various simulation teaching methods of intubation

\section{Methods}

Anesthesiology 251 clinical clerk students (8 students per block, 20 blocks) underwent their 2 -week rotation in the department of anesthesiology and were shown a 6-minute video describing how to do proper intubation. Each block was exposed to either of the following education: videoassisted learning (V), video-assisted learning with guided simulation (VGL), and video-assisted learning with experiential learning (VEL). Each student was assessed by a non-graded practical evaluation at the end of the first week of rotation. Then they were exposed to both VGL and VEL at the end of the practical evaluation to equalize learning exposures among students.

All students participated in the conduct of study. Strict confidentiality of grades and video recordings was implemented.

The three learning strategies were defined as follows:

1. Video-assisted learning exposed the student initially and only to instructional video. The student was not exposed to simulation models to practice intubation.

2. Video-assisted learning with guided simulation exposed students to an instructional video to be followed by practice intubation on simulation models being guided by a consultant anesthesiologist. The instructor followed an instructional module in guiding the student. The student practiced after the demonstration in two sessions.

3. Video-assisted learning with experiential learning exposed students to an instructional video followed by free time to practice intubation on simulation models on their own. The simulation models were available for the students to practice for two sessions anytime from the first day to the last day of the first week of rotation.

Non-graded video recorded OSCE (Table 1) was done at the end of the first week of rotation to assess competency. OSCE scoring was done by an independent reviewer viewing the video.

Table 1. Practical evaluation for assessing intubation

\begin{tabular}{|c|c|c|c|}
\hline Checklist & Done & Not Done & Remark(s) \\
\hline \multicolumn{4}{|l|}{ Checked that the laryngoscope is in proper working order } \\
\hline \multicolumn{4}{|l|}{ Checked the endotracheal tube and cuff for leaks; inserted the stylet } \\
\hline \multicolumn{4}{|l|}{ Positioned the patient's head properly (sniffing position) } \\
\hline \multicolumn{4}{|l|}{ Opened the mouth widely (scissor finger maneuver or opened jaw widely by pressing down on the lower mandible) } \\
\hline \multicolumn{4}{|l|}{ Inserted the laryngoscope blade into the patient's mouth while displacing the patient's tongue laterally } \\
\hline \multicolumn{4}{|l|}{ Elevated the patient's mandible with the laryngoscope without using the patient's teeth as a fulcrum } \\
\hline \multicolumn{4}{|l|}{ Introduced the endotracheal tube and advanced the tube to the proper depth } \\
\hline \multicolumn{4}{|l|}{ Inflated the cuff to the proper pressure } \\
\hline \multicolumn{4}{|l|}{ Directed the assistant to ventilate the patient } \\
\hline \multicolumn{4}{|l|}{$\begin{array}{l}\text { Confirmed proper placement of endotracheal tube by auscultation for bilateral equal breath sounds and absence of air } \\
\text { entry over the epigastrium ("successful intubation") }\end{array}$} \\
\hline Secured the endotracheal tube & & & \\
\hline
\end{tabular}

Critical Criteria: The student gets only $50 \%$ of his/her score above if:

1. Unable to intubate after 3 attempts or unable to intubate in 3 minutes

2. Unable to recognize esophageal intubation 
Table 2. Mean scores for Intubation OSCE and Proportion of Failure of Intubation

\begin{tabular}{lccc}
\hline \multicolumn{1}{c}{ Learning Strategy } & Mean score (11 points) & Score Standard Deviation & Failure of intubation \\
\hline Video-assisted learning & 5.76 & 2.16 & $21 \%(8 / 38)$ \\
Video-assisted learning with instructor-guided simulation & 7.21 & 2.35 & $2 \%(1 / 40)$ \\
Video-assisted learning with experiential learning & 7.60 & \multirow{2}{*}{1.72} & $0 \%(0 / 36)$ \\
(self-discovery learning) simulation & & & 0 \\
\hline
\end{tabular}

Table 3. Three-way T test for OSCE scores, Chi2 test for OSCE scores

\begin{tabular}{|c|c|c|c|c|}
\hline Learning Strategy & $\begin{array}{c}\text { Difference of mean score } \\
(95 \% \mathrm{CI})\end{array}$ & P value & $\begin{array}{l}\text { Absolute risk reduction } \\
\text { (failure of intubation) }\end{array}$ & $P$ value \\
\hline V vs VGL & $2.05(0.92-3.17)$ & 0.0006 & $0.27(0.07-0.49)$ & 0.0190 \\
\hline V vs VEL & $1.75(0.73-2.70)$ & 0.0014 & $0.30(0.10-0.52)$ & 0.0110 \\
\hline VGL vs VEL & $0.30(-1.28-0.68)$ & 0.5504 & $0.03(-0.10-0.15)$ & 0.8530 \\
\hline
\end{tabular}

a V - video-assisted learning, VGL - video-assisted learning with instructor-guided learning simulation, VEL - video-assisted learning with experiential learning (self-discovery) simulation

Cross-exposure to guided learning and to experiential learning was done on the second week of rotation. On the second week of rotation, a two-day session of instructorguided intubation using a simulation model, and unlimited access to simulation model were given to the students.

The cross-exposure to all interventions was done so as not to affect the graded practical exam given at the last day of the two-week rotation.

Intubation practical exam mean scores (skill process) and proportion of successful intubation (skill product) were compared between interventions. Failure of intubation was defined as unable to intubate after 3 attempts, unable to intubate in 3 minutes or unable to recognize esophageal intubation. Students in each block were randomly interviewed to explore their experiences in the three different interventions.

\section{Ethical Considerations}

The study was on medical education involving maneuvers in teaching methods. The grade of the students were not affected during the experimentation. No harm to students was expected. The study was approved by the Dean of the College of Medicine and the institutional review board (University of the Philippines-Manila Research Ethics Board).

The patients were not directly involved in the conduct of this study. Only simulation models were used. However, the purpose of the study was to allow students to acquire greater competency levels prior to actual patient exposure.

\section{Results and Discussion}

The three learning strategies: 1. Video-assisted learning, 2. Video-assisted learning with instructor-guided simulation, 3. Video-assisted learning with experiential learning (selfdiscovery learning) simulation showed OSCE score means (standard deviations) of 5.76 (2.16), 7.21 (2.35) and 7.60 (1.72), respectively. Failure of intubation was $21 \%$ (8/38), $2 \%$ (1/40) and $0 \%(0 / 36)$, respectively. (Table 2).

The use of instructor-guided simulation or experiential learning enhanced student performance, e.g. OSCE scores and failure of procedure during intubation compared to video instructions alone. The OSCE scores were higher by approximately 2 out of eleven points for both simulation groups. Both simulation groups prevented failure of intubation by $30 \%$. However, there seems to be no statistically significant difference between instructor-guided simulation and experiential (self-directed) learning simulation. (Table 3).

\section{Focus Group Discussion}

A 45-minute focus group discussion was conducted with four LU 6 students who had completed the Anesthesiology clerkship rotation. Focus group questions covered students' experiences with the simulation-based learning activities, perceived benefits of the learning interventions, and feedback for improving future implementation of simulation-based learning. Scripted, open-ended questions were used to promote discussion and encourage all participants to contribute. One investigator who was blinded to the learning interventions received by the participants served as the discussion facilitator. The discussion was recorded in digital audio and transcribed, and all data were anonymized. The facilitator analyzed the transcript of the focus group discussion using structural coding of the responses with the key features of effective instructional design of simulation-based education identified in the meta-analysis by Cook, et al. serving as the conceptual framework. ${ }^{1,8}$

Students recognized the contribution of the simulationbased activities to the development of their intubation skills particularly the affordance to practice and receive feedback on performing the steps of intubation before doing the procedure with real patients. They appreciated the opportunity to actually perform intubation in a rehearsal setting before doing the procedure on real patients. The intubation practice session with the mannequin was viewed as an important opportunity to become mentally and physically familiar with the steps in the intubation sequence, after viewing the instructional video and the live demonstration. Similarly, the students appreciated the feedback provided by the clinical teachers during the simulation exercises, especially citing the usefulness of 
corrective guidance given by the resident monitors. The students asserted that the practice and feedback sessions promoted a higher level of mental and physical readiness for doing the procedure, which in turn, helped minimize errors when intubating real patients.

A limitation of the study was the inability to simulate determination of cuff pressure. The ideal intubation cuff pressure is $20-30 \mathrm{~cm} \mathrm{H}_{2} \mathrm{O}$. It has been shown that the ability to estimate proper cuff pressure by palpation was less sufficient $68 \%$ of the time. This can be augmented by participation in emergency courses if a cuff pressure measuring device was not readily available. ${ }^{9}$

New technology allows indirect visualization of airway using video-laryngoscopes. In a study of 1,200 endotracheal intubations, the use of video-laryngoscope compared to direct laryngoscope resulted to 98 vs $81 \%(\mathrm{p}<0.0001)$ success rate among novices, and 97 vs $83 \% \quad(p=0.0002)$ among experts. ${ }^{10}$ However, until the time that a video-laryngoscope becomes standard practice and readily available, the use of direct laryngoscope for endotracheal intubation with simulation using mannequins may provide high success rate of intubation as shown in this study (98 to 100\%).

\section{Conclusion}

Medical simulation enhanced student skills development. Experiential learning or self-discovery learning method may be as effective as instructor-guided simulation in the development of intubation skills.

\section{Acknowledgments}

Thanks are given to Dean Agnes Mejia of the UP College of Medicine for spearheading patient safety studies, Dr. Loreto Fellizar of the Department of Anesthesiology and Dr. Lanie Nicodemus of the Medical Simulation Unit for making this study possible.

\section{Statement of Authorship}

All authors have approved the final version submitted.

\section{Author Disclosure}

All the authors declared no conflicts of interest.

\section{Funding Source}

This paper was funded by the University of the Philippines College of Medicine.

\section{References}

1. Cook DA, Brydges R, Hamstra SJ, et al. Comparative effectiveness of technology-enhanced simulation versus other instructional methods: a systematic review and meta-analysis. Simul Healthc. 2012; 7(5):308-20. doi:10.1097/SIH.0b013e3182614f95.

2. Cook DA, Hatala R, Brydges R, et al. Technology-enhanced simulation for health professions education: a systematic review and meta-analysis. JAMA. 2011; 306(9):978-88. doi:10.1001/jama.2011.1234.

3. Ti LK, Chen FG, Tan GM, et al. Experiential learning improves the learning and retention of endotracheal intubation. Med Educ. 2009; 43(7):654-60.

4. Lee DH, Kim JG, Kim CW, Lee CH, Lim JH. The usefulness of 3Dimensional virtual simulation using haptics in training orotracheal intubation. BioMed Res Int. 2013; 2013:534097. http://dx.doi.org/10.1155/ 2013/534097.

5. Mayo PH, Hegde A, Eisen LA, Kory P, Doelken P. A program to improve the quality of emergency endotracheal intubation. J Intensive Care Med. 2011; 26(1):50-6. doi:10.1177/0885066610384070.

6. Kuduvalli PM, Jervis A, Tighe SQ, Robin NM. Unanticipated difficult airway management in anaesthetised patients: a prospective study of the effect of mannequin training on management strategies and skill retention. Anaesthesia. 2008; 63(4):364-9. doi:10.1111/j.1365-2044.2007.05353.x.

7. Russo SG, Eich C, Barwing J, et al. Self-reported changes in attitude and behavior after attending a simulation-aided airway management course. J Clin Anesth. 2007; 19(7):517-22.

8. Saldana J. The coding manual for qualitative researchers. London: SAGE; 2013.

9. Giusti GD, Rogari C, Gili A, Nisi F. Cuff pressure monitoring by manual palpation in intubated patients: How accurate is it? A manikin simulation study. Aust Crit Care. 2017; 30(4):234-8. doi:10.10.16/j. aucc.2016.10.001.

10. Declercq PL, Bubenheim M, Gelinotte S, et al. Usefulness of videolaryngoscopy with the airway scope for intubation performance and learning: an experimental manikin controlled study. Ann Intensive Care. 2016; 6(1):83. doi:10.1186/s13613-016-0182-0. 